\title{
Analysis of Residual Stress in Hot Rolled H-beams*
}

\section{By Hiroshi YOSHID $A^{* *}$}

\begin{abstract}
Synopsis
To analyze longitudinal residual stress in hot rolled $\mathrm{H}$-beams, a numerical method for the prediction of temperature and thermal stress has been developed by taking phase transformation into account. The temperature during cooling and the residual stress calculated by the present method agree well with the measured ones. The influence of finishing temperature and cross-sectional size on the residual stress was investigated by using this method. The results obtained are as follows;

(1) The larger the thickness ratio of flange to web $\left(t_{f} / t_{w}\right)$ is, the larger the stress $i$.

(2) The larger the difference in finishing temperature between web and flange $\left(T_{f 0}-T_{w 0}\right)$ is, the larger the stress is.

(3) The larger the ratio of cross-sectional area of flange to web $\left(S_{f}\right)$ $\left.S_{w}\right)$ is, the smaller the tensile stress in the flange is and the larger the compressive stress in the web is.

(4) Immediately after rolling, the less the non-transformed phase (austenite) in the web is and the more the phase in the flange is, the larger the stress is.

(5) The larger the compressive stress in the web is and the larger the ratio of inner width to thickness in the web $\left(B_{w} / t_{w}\right)$ is, the more frequently the web-buckling occurs.
\end{abstract}

\section{Introduction}

The longitudinal residual stress in hot rolled $\mathrm{H}$ beams is tension in the flange and compression in the web. When the residual stress becomes large, the following problems arise;

1) The occurrence of inferior goods which are buckled in the web

2) The occurrence of shape defects and cracks during the secondary deformation

3) The lowering in proof strength as structural material.

The cross-sectional distributions of finishing temperature and of cooling rate after rolling are considered the cause of residual stress. Therefore the following measures have been suggested for reducing the residual stress;

a) Flange-cooling by water before or after the finishing rolling ${ }^{1,2)}$

b) Web-warming by using a plate-cover over the web before the finishing rolling ${ }^{3}$

c) Web-warming by using an insulator on the web or web-heating by gas after the finishing rolling

d) Shortening the distance between H-beams cooled in the I-shape form on the cooling bed.

The knowledge of temperature and thermal stress in all areas during cooling is necessary for applying these measures effectively. As it is impossible to measure the temperature and stress in all areas, the knowledge of them have to be obtained by calculation. In the calculation ${ }^{4,5}$ published previously, however, the phenomenon of phase transformation which has a great influence on both the temperature and the stress is not closely taken into consideration. Namely, a generating heat by the transformation is ignored and material properties, such as specific heat, thermal conductivity and coefficient of thermal expansion, are supposed to depend only on temperature without regard to the ratio of the transformation. On the other hand, if the transformation phenomenon during cooling is known in detail, it is possible to predict material qualities, such as hardness, strength and elongation at room temperature, even in the case of cooling control and heat treatment.

Therefore a numerical method for calculating the phase transformation simultaneously as well as the temperature and thermal stress has been developed. Then the influence of finishing temperature and sectional size on the residual stress in the H-beams was investigated using this method.

\section{Calculation Method}

The knowledge of the cross-sectional temperature distribution at all times is necessary for calculating the thermal stress and strain. As it is impossible to measure the cooling curve in each part of the crosssection, the temperature distribution was calculated. It is known that the phenomenon of phase transformation has a great influence on the temperature, thermal stress and strain during cooling. Therefore the calculation of the transformation was carried out simultaneously with those calculations. Regarding the detail of the method, the author's previous report $^{6,7)}$ should be consulted.

\section{Calculation of Temperature}

The cross-sectional temperature distribution is calculated by solving the two-dimensional Fourier's equation with a term of generating heat by phase transformation using a special finite-difference calculus called the IAD method. ${ }^{8}$

\section{Calculation of Thermal Stress and Strain}

As a rolled H-beam is long and thin, only the stress and strain in the longitudinal direction are taken into consideration. Then it is assumed that the crosssection keeps a plane during cooling.

There are three kinds of strain. One is thermal

* Originally published in Tetsu-to-Hagané, 69 (1983), 412, in Japanese; Formerly presented to the 101st ISIJ Meeting, April 1981, S301, at The University of Tokyo in Tokyo. English version received October 31, 1983. (C) 1984 ISIJ

** Formerly Mizushima Research Dept., Research Laboratories, Kawasaki Steel Corporation. Now at Research Laboratories, Kawasaki Steel Corporation, Kawasaki-cho, Chiba 260. 
expansion strain which shows the amount of thermal contraction. Another is elastic strain which is directly related to thermal stress. The other is plastic strain which is decided by a limit condition that thermal stress cannot become larger than yield stress.

\section{Criterion of Occurrence of Web-buckling}

When the residual compressive stress in the web becomes large, the web is buckled. In that case, the $\mathrm{H}$-beam is worthless as a product.

The occurrence of web-buckling is judged by comparing the compressive thermal stress with the critical buckling stress. The critical buckling stress in a long and thin plate is calculated by the following equation when the buckling occurs under a homogeneous compressive stress.

$$
\sigma_{\mathrm{cr}}=\frac{E \cdot \pi^{2}}{3\left(1-\nu^{2}\right)}\left(\frac{h}{b}\right)^{2}
$$

where, $v$ : Poisson's ratio $(0.27)$

\section{$h:$ thickness}

$b$ : width

$b$ is regarded as the width where the thermal stress is compressive. The mean compressive stress $\bar{\sigma}$ is compared with $\sigma_{\text {cr }}$ by Eq. (1). Then if $\bar{\sigma}$ is larger than $\sigma_{\mathrm{cr}}$, the buckling occurs.

\section{Calculation of Phase Transformation}

The transformation is calculated by a method ${ }^{9)}$ which utilizes a time-temperature-transformation (TTT) diagram for the estimation of the transformation in an arbitrary cooling curve. In this method, a cooling curve is approximated with stages of a temperature-time curve and the progress of the transformation is traced on the TTT diagram which is expressed as a function ${ }^{10}$ ) of austenite $(\gamma)$ grain size and chemical compositions. Scheil's method ${ }^{11)}$ is used to judge when the transformation begins.

\section{Division}

A quarter of the cross-section is divided into 124 elements as shown in Fig. 1. In order to calculate the temperature in a short time, areas with rapid change and areas with slow change are divided finely and coarsely, respectively. The fillet part is approximated with an isosceles right-angled triangle.

The time-increment is also made finer at points where rapid cooling occurs than at points where slow cooling occurs.

\section{Material Properties}

The previous report ${ }^{6,7}$ ) and the literature ${ }^{12-17}$ ) should be consulted with regard to temperature dependence of material properties such as specific heat, latent heat of $\gamma \rightarrow \alpha$ transformation, thermal conductivity, coefficient of thermal expansion, Young's modulus and yield stress which are used for the calculation of temperature and thermal stress.

The heat transfer coefficient during air-cooling $(H)$, which is necessary for calculating the heat flow on the surface, is given as a sum of $H_{\mathrm{rad}}$ (a term of radiation which is introduced from Stefan-Boltz-

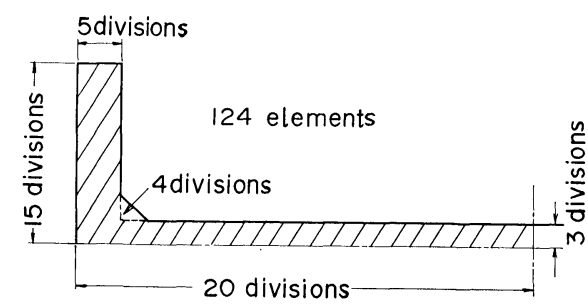

Fig. 1. Division for the calculation in $1 / 4$ section of $\mathrm{H}$ beam.

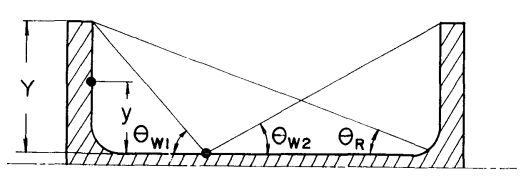

Fig. 2. Geometric factors for the modification of heat transfer coefficient.

mann's law) and $H_{\text {conv }}$ (a term of convection). Here, it is assumed that $H_{\text {conv }}\left(7.5 \mathrm{kcal} / \mathrm{m}^{2} \cdot \mathrm{h} \cdot{ }^{\circ} \mathrm{G}\right)$ is independent of the surface temperature. As the thermal radiation in the web surface and that in the inner surface of the flange interfere with each other, a shape factor $(F)$ which modifies $H$ is introduced. Figure 2 shows geometric factors for the modification.

$$
\begin{aligned}
& H=F\left(H_{\text {rad }}+H_{\text {conv }}\right) \\
& H_{\mathrm{rad}}=\varepsilon_{m} \cdot C_{s} \cdot\left\{\left(T_{s}+273\right)^{2}+\left(T_{\mathrm{atm}}+273\right)^{2}\right\} \\
& \times\left(T_{s}+T_{\text {atm }}+546\right) \\
& F=\left\{\begin{array}{c}
0.5 F_{\mathrm{C}}\left\{\cos \left(\theta_{w 1}\right)+\cos \left(\theta_{w 2}\right)\right\} \\
(\text { Web surface }) \\
\left\{1-0.5 F_{c} \cdot \cos \left(\theta_{R}\right)\right\} \frac{y}{Y}+0.5 F_{C} \cdot \cos \left(\theta_{R}\right)
\end{array}\right. \\
& \text { (Flange inner surface) } \\
& 1 \text { (Other surface) }
\end{aligned}
$$

$$
F_{c}= \begin{cases}0.8 & (\text { E type H-beam }) \\ 1.0 & (\text { B type H-beam })\end{cases}
$$

where, $\varepsilon_{m}$ : emissivity

$C_{s}:$ Stefan-Boltzmann constant

$T_{s}:$ surface temperature

$T_{\text {atm }}:$ atmosphere temperature

The value of $\varepsilon_{m}$ used in Eq. (3) was decided by considering both the literature ${ }^{18)}$ and measured values of the surface temperature during cooling.

\section{Whole Flow of Calculation}

Figure 3 shows the whole flow of the calculation. We attempt to calculate an unknown state at $t_{n}$ from a known state at $t_{n-1}$. First, the transformation ratio and the material properties are calculated using a predicted temperature $T_{i, j, n}^{\prime}$. Next, the temperature $T_{i, j, n}$ is calculated using the IAD method. If the calculated temperature $T_{i, j, n}$ is nearly equal to the predicted one $T_{i, j, n}^{\prime}$, the thermal stress, strain and flatness (webbuckling) are calculated. Then the calculation of a state at the next step $(n=n+1)$ is carried out in the same way. If $T_{i, j, n}$ is different from $T_{i, j, n}^{\prime}, T_{i, j, n}^{\prime}$ is replaced with $\mathcal{T}_{i, j, n}$ and then the calculations of trans- 
formation and material properties are repeated. Namely, in the case of this method the temperature and the transformation ratio are decided virtually simultaneously.

\section{Comparison between Calculated and Measured Values}

In the calculation the temperature and the thermal stress during cooling in each area of the cross-section are obtained, but in the measurement only the cooling curve at the surface and the thermal stress at room temperature (the residual stress) are obtained. Therefore the comparison between calculated and

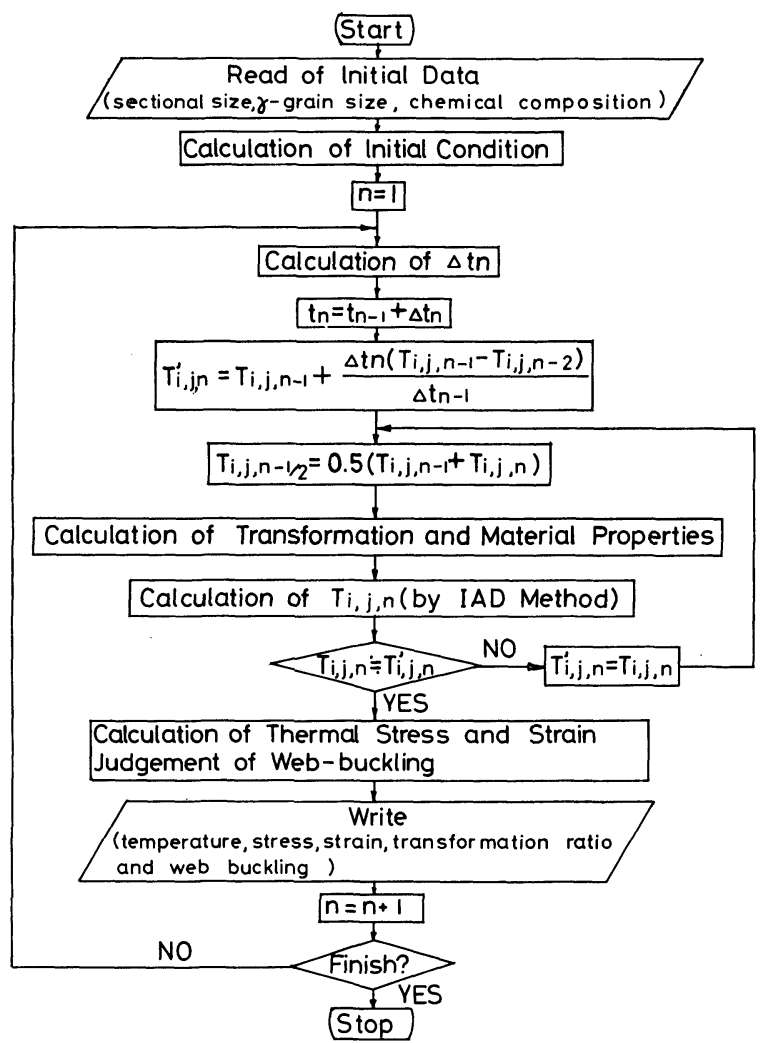

Fig. 3. Whole flow chart of the computer program for the analysis of temperature, stress, strain, transformation and web-buckling. measured values in the cooling curve at the surface and the comparison in the residual stress were carried out.

\section{Cooling Curve}

An H-beam, the cross-sectional size of which is $200 \mathrm{~mm}$ in web height, $200 \mathrm{~mm}$ in flange width, $8 \mathrm{~mm}$ in web thickness and $12 \mathrm{~mm}$ in flange thickness ( $\mathrm{H}: 200 \times 200 \times 8 \times 12)$, is cut into a $500 \mathrm{~mm}$ length. CA thermo-couples were attached to a quarter way across the outer surface of the flange width and half way across the surface of the web in a position of $250 \mathrm{~mm}$ from the cut edge-surface. This material was heated by a batch furnace. When the temperature of the flange and of the web became 1025 and $985^{\circ} \mathrm{C}$, respectively, it was extruded from the furnace. Immediately after that, the temperature during air-cooling was measured by the thermocouples.

In a rolled H-beam $(\mathrm{H}: 912 \times 302 \times 18 \times 34)$, the temperatures during air-cooling after rolling at the same points as mentioned above were measured on a run-out table by radiation thermometers.

Figures 4 and 5 show the comparison between the

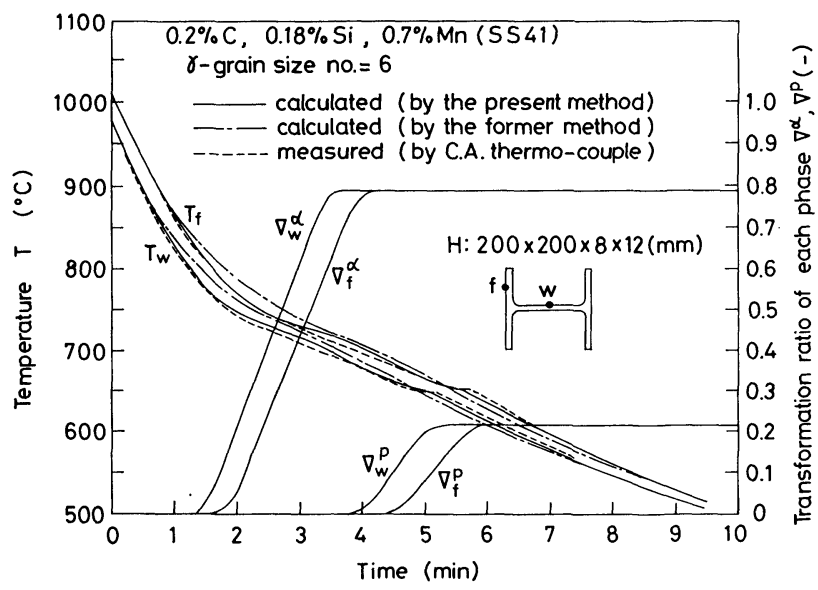

Fig. 4. Comparison between calculated and measured surface temperatures in a $200 \times 200 \times 8 \times 12 \mathrm{~mm} \mathrm{H}$ beam.
Fig. 5.

Comparison between calculated and measured surface temperatures in a $912 \times 302 \times 18$ $\times 34 \mathrm{~mm}$ H-beam.

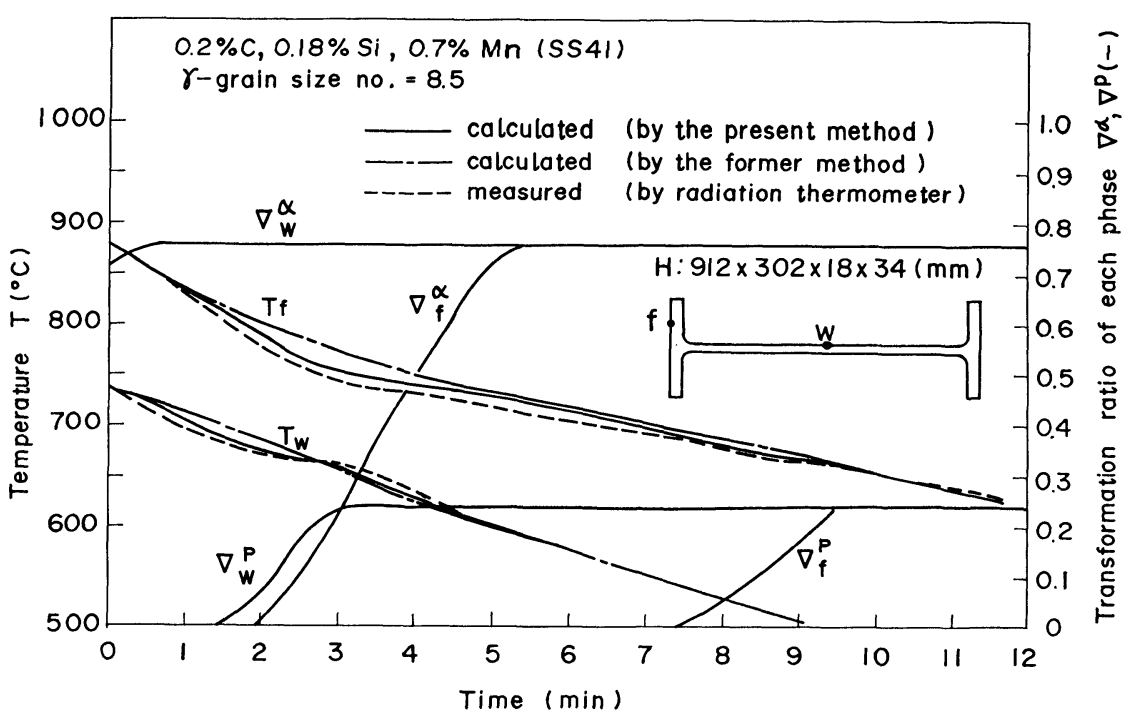


measured and calculated temperatures. In both figures, two calculated cooling curves are shown. One is a cooling curve calculated by the present method and the other is a cooling curve calculated by the former method $^{4,5)}$ where apparent specific heat with latent heat of the transformation and thermal conductivity in an equilibrium state of the transformation are used. In the calculation of the rolled $\mathrm{H}$ beam (Fig. 5), it is assumed that the transformation estimated from a diagram for equilibrium transformation is proceeding immediately after rolling. As shown in the figures, the curves calculated by the present method agrees well with the measured curves. In the case of the former method, however, a good agreement is not obtained especially with regard to the cooling retardation in the period of the transformation.

\section{Thermal Stress at Room Temperature (Residual Stress)}

Figure 6 shows the comparison between calculated and measured residual stresses in large size H-beams where the residual stresses are large and the webbucklings are often observed. The calculation begins immediately after rolling. At that time, the thermal stress and the strains are assumed to be zero. As shown in the figure, the residual stresses calculated by the present method agree well with the measured stresses. The stresses calculated by the former method, however, are greater than the measured stresses. With regard to the compressive stresses in the fillet part of the web, the calculated values are greater than the measured values even in the case of the present method. This is because the crosssectional distribution of finishing temperature is treated simply in the calculation. Namely, the finishing temperatures of the flange and the web are

$$
H: 800 \times 300 \times 14 \times 26(\mathrm{~mm})
$$
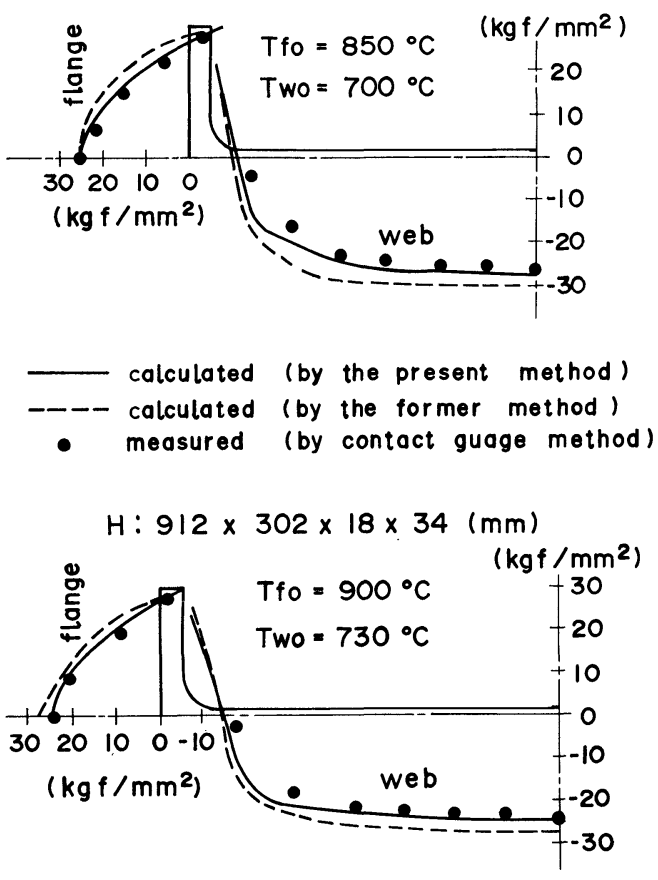

Fig. 6. Comparison between calculated and measured residual stresses in large $\mathrm{H}$-beams. assumed to be homogeneous $\left(T_{f 0}\right.$ and $T_{w 0}$, respectively), though actually the temperature in the fillet part of the web is much higher than the temperature in the other parts of the web.

Judging from the above-mentioned results, it is concluded that the analysis of residual stress in rolled H-beams is carried out accurately by the present method with consideration of phase transformation.

\section{Effects of Sectional Size and Finishing Temperature on Residual Stress}

It is well known that the residual stress is greatly influenced by the size and the finishing temperature. These effects have been analyzed by the present method.

\section{Conditions for Calculation}

Table 1 shows calculation conditions selected for the investigation. Large E-type H-beams, where the residual stresses are large and the web-bucklings are often observed, were chosen as objects of the investigation. The condition of finishing temperature was decided on the premise that either flangecooling by water ${ }^{1)}$ or web-warming by using a platecover $^{3)}$ would be carried out before the finishing rolling. The H-beams after the finishing rolling were assumed to be air-cooled.

\section{Calculation Results and Discussion}

As typical examples of calculation results, changes in temperature, thermal stress, plastic strain and ratio of phase transformation (mean values in thickness) at a quarter of the flange width and at a half of the web height during cooling after the rolling are shown in Figs. 7 and 8 . Figure 7 is the result under various sectional sizes $\left(W_{f}=300 \mathrm{~mm}, H_{w 0}=900,700,588 \mathrm{~mm}\right.$ ) and a fixed finishing temperature $\left(\mathcal{T}_{f 0}=850{ }^{\circ} \mathrm{C}, T_{w 0}=\right.$ $700^{\circ} \mathrm{C}$. Figure 8 is the result under various finishing temperature (@) $T_{f 0}=900^{\circ} \mathrm{C}, T_{w 0}=750{ }^{\circ} \mathrm{C}$, (b) $T_{f 0}=$

Table 1. Calculation conditions selected to investigate the influence of sectional size and finishing temperature on the residual stress.

\begin{tabular}{|c|c|c|c|c|c|c|c|}
\hline \multicolumn{5}{|c|}{ Sectional size $(\mathrm{mm})$} & \multicolumn{3}{|c|}{$\begin{array}{c}\text { Finishing temperature } \\
\left({ }^{\circ} \mathrm{C}\right)\end{array}$} \\
\hline$H_{w}$ & $W_{f}$ & $t_{w}$ & $t_{f}$ & $R$ & $T_{f 0}$ & $T_{w 0}$ & $\begin{array}{c}T_{f 0}- \\
T_{w 0}\end{array}$ \\
\hline 900 & \multirow{4}{*}{300} & 16 & 28 & & \multirow{8}{*}{$\begin{array}{l}750 \\
? \\
950\end{array}$} & \multirow{5}{*}{$\begin{array}{c}650 \\
? \\
750\end{array}$} & \multirow{5}{*}{$\begin{array}{c}100 \\
? \\
200\end{array}$} \\
\hline 800 & & 14 & 26 & 79 & & & \\
\hline 700 & & 13 & 24 & 28 & & & \\
\hline 588 & & 12 & 20 & & & & \\
\hline 600 & \multirow{4}{*}{200} & 11 & 17 & 22 & & & \\
\hline 500 & & 10 & 16 & 20 & & \multirow{3}{*}{$\begin{array}{c}700 \\
2 \\
800\end{array}$} & \multirow{3}{*}{$\begin{array}{c}50 \\
? \\
150\end{array}$} \\
\hline 450 & & 9 & 14 & 18 & & & \\
\hline 400 & & 8 & 13 & 16 & & & \\
\hline
\end{tabular}


Fig. 7.

Changes in temperature, thermal stress, plastic strain and ratio of phase transformation (mean values in thickness) during cooling under various sectional sizes.

Fig. 8 .

Changes in temperature, thermal stress, plastic strain and ratio of phase transformation (mean values in thickness) during cooling under various finishing temperatures.
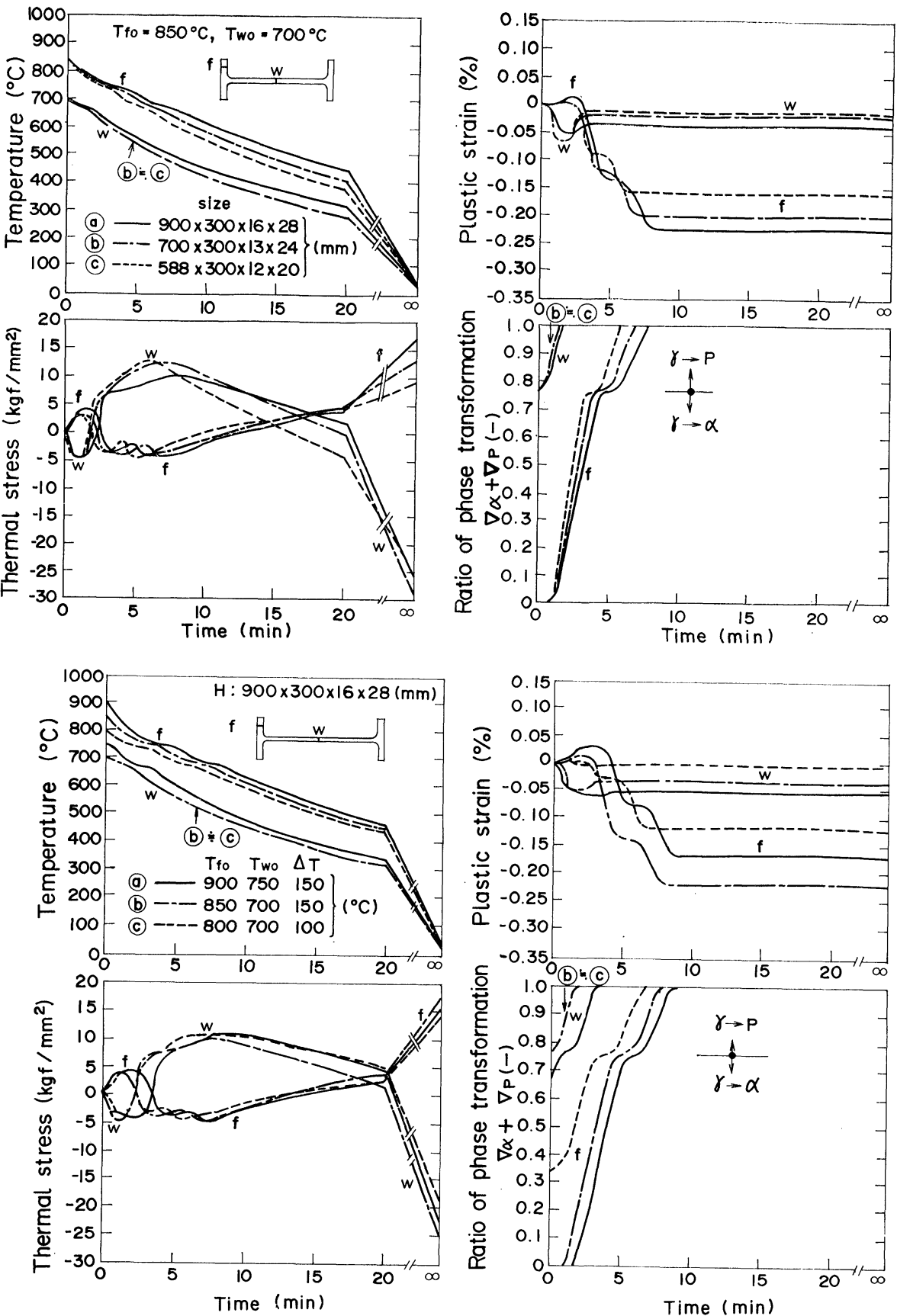

$850{ }^{\circ} \mathrm{C}, \mathcal{T}_{w 0}=700^{\circ} \mathrm{C}$, (c) $T_{f 0}=800^{\circ} \mathrm{C}, T_{w 0}=700^{\circ} \mathrm{C}$ ) and a fixed sectional size $(H: 900 \times 300 \times 16 \times 28 \mathrm{~mm})$.

Figure 9 shows the mean values of residual stress in the thickness under various conditions.

The outline of the results is as follows;

(1) In cooling curves, the cooling retardation by the transformation from austenite to ferrite and pearlite is observed. As a matter of course, the smaller the size is, the faster the cooling is.

(2) The thermal stress during cooling shows three changes of tension $\rightarrow$ compression $\rightarrow$ tension in the flange and compression $\rightarrow$ tension $\rightarrow$ compression in the web. The lower the finishing temperature is and the smaller the size is, the faster these changes occur. The first change (the tension in the flange and the compression in the web) and the next converse change correspond to the transformation in the web and the flange, respectively. Namely, in the area where the rate of the transformation is faster, compressive stress appears and in the area where the rate is slower, tensile stress appears, because the transformation causes both dilatation and generation of heat.

(3) The minimum values of thermal stress in the web and the flange during cooling are almost constant $\left(-4 \sim-5 \mathrm{kgf} / \mathrm{mm}^{2}\right)$ irrespective of the size and the finishing temperature. This is because the thermal stress reaches the yield stress during the transformation and the temperature at that time is almost constant $\left(650 \sim 680^{\circ} \mathrm{C}\right)$.

(4) The lower the finishing temperature is and the smaller the size is, the faster the change of plastic strain during cooling occurs. The pattern of the change, however, is similar. Namely, when the transformation proceeds mainly in the web, the plastic deformation is compressive in the web and tensile 

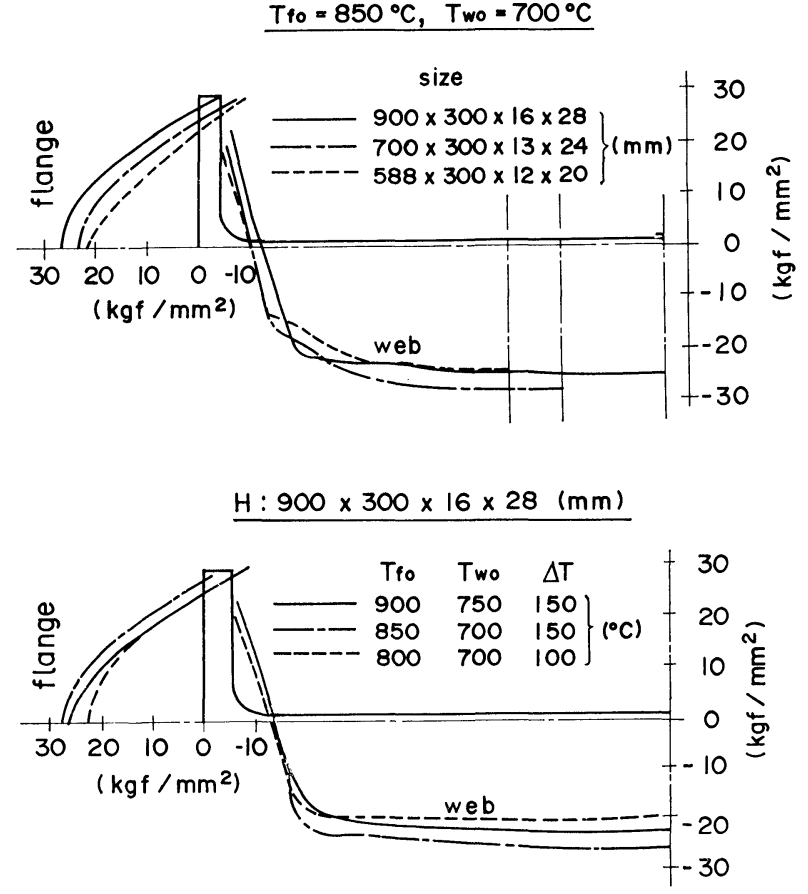

Fig. 9. Residual stresses (mean values in thickness) under various conditions.

in the flange. Conversely when the transformation proceeds mainly in the flange, the deformation is tensile in the web and compressive in the flange. The plastic deformation does not occur after the finish of the transformation in all areas of the cross-section.

(5) The lower the finishing temperature is and the smaller the size is, the faster the transformation proceeds. In the cross-section, the transformation of the web proceeds faster than that of the flange.

(6) The maximum value of residual stress (mean values in thickness) appears at the center of the flange and the minimum value appears at the center of the web. The tensile residual stress in the flange becomes smaller as the position approaches the edge and changes into compressive stress at the edge. The compressive stress in the web becomes smaller as the position approaches the fillet and changes into tensile stress in the fillet.

(7) The larger the difference in finishing temperature between web and flange is, the larger the residual stress is. The influence of size on the residual stress, however, is not so simple as the influence of finishing temperature is.

(8) As an index of web-buckling $\left(\bar{\sigma}_{w} / \sigma_{\mathrm{cr}}\right)$ is less than 1.0 under the present conditions for calculation, the web-buckling does not occur.

To investigate the influences of size and finishing temperature on the residual stress and the webbuckling in detail, the multiple regression analysis; where the stress at the center of the flange width $\left(\sigma_{f 1 / 2}\right)$, that of the web height $\left(\sigma_{w 1 / 2}\right)$ and the index $\left(\bar{\sigma}_{w} / \sigma_{\mathrm{cr}}\right)$ were considered dependent variables; was carried out using various factors (independent variables) of size and finishing temperature,

The multiple regression equations obtained finally are as follows:

$$
\begin{aligned}
& \sigma_{f 1 / 2}\left(\mathrm{kgf} / \mathrm{mm}^{2}\right)=-4.61+25.9 * \ln \left(\begin{array}{c}
t_{f} \\
t_{W}
\end{array}\right) \\
& +3.79 * \ln \left(T_{f 0}-T_{W 0}\right)-11.0 * \ln \left(\begin{array}{c}
S_{f} \\
S_{W}
\end{array}\right) \\
& -0.00025 * \Delta T_{w}^{2}-0.00052 * \Delta T_{f}^{2} \\
& \sigma_{w 1 / 2}\left(\mathrm{kgf} / \mathrm{mm}^{2}\right)=28.8-36.6 * \ln \left(\begin{array}{c}
t_{f} \\
t_{w}
\end{array}\right) \\
& -6.92 * \ln \left(T_{f 0}-T_{w 0}\right)+0.0850 * \Delta T_{w} \\
& +0.0559 * \Delta T_{f} \\
& \left(\begin{array}{c}
\bar{\sigma}_{w} \\
\sigma_{\mathrm{cr}}
\end{array}\right)=-1.36+1.14 * \ln \left(\begin{array}{c}
t_{f} \\
t_{w}
\end{array}\right) \\
& +0.154 * \ln \left(T_{f 0}-T_{w 0}\right)+0.00027 *\left(\frac{B_{W}}{t_{w}}\right)^{2} \\
& -0.0200 * \sqrt{\Delta T_{W}}-0.00001 * \Delta T_{f}^{2} \\
& \Delta T_{W}=\left\{\begin{array}{lll}
0 & \text { if } & T_{W 0}<T_{A 1} \\
T_{W 0}-T_{A 1} & \text { if } & T_{W 0} \geq T_{A 1},
\end{array}\right. \\
& \Delta_{\Lambda f}=\left\{\begin{array}{lll}
T_{A 3}-T_{f 0} & \text { if } & T_{f 0}<T_{A 3} \\
0 & \text { if } & T_{f 0} \geq T_{A 3}
\end{array}\right.
\end{aligned}
$$

where, $\quad t_{f}, t_{w}$ : thicknesses of flange and web (mm) $S_{f}, S_{w}$ : cross-sectional areas of flange and web $\left(\mathrm{mm}^{2}\right)$

$T_{f 0}, T_{w 0}$ : finishing temperatures of flange and web $\left({ }^{\circ} \mathrm{C}\right)$

$B_{w}$ : inner width of web $(\mathrm{mm})$

$T_{A 3}, T_{A 1}$ : start and finish temperature of phase transformation in the equilibrium transformation diagram $\left({ }^{\circ} \mathrm{C}\right)\left(\mathrm{SS} 41: 849\right.$ and $\left.722{ }^{\circ} \mathrm{C}\right)$

The accuracies of the above-mentioned equations are very good, as the coefficients of multiple correlation are $0.97 \sim 0.99$, the standard deviations of residual stress and the deviation of web-buckling index are $1.1 \sim 1.2 \mathrm{kgf} / \mathrm{mm}^{2}$ and 0.04 , respectively. Therefore the above equations can be used effectively as simplified equations for their prediction.

The results obtained by the multiple regression analysis are as follows:

(1) The thickness ratio of flange to web $\left(t_{f} / t_{w}\right)$, the difference in finishing temperature between web and flange $\left(T_{f 0}-T_{w 0}\right)$, the difference between the finishing temperature in web and the finish temperature of $\gamma \rightarrow \alpha$ transformation $\left(\Delta T_{w}=T_{w 0}-T_{A 1}\right)$ and the difference between the start temperature of the transformation and the finishing temperature in flange $\left(\Delta T_{f}=T_{A 3}-T_{f 0}\right)$ closely correlate with the residual stress and the web-buckling. Also the ratio of cross-sectional area of flange to web $\left(S_{f} / S_{w}\right)$ and the ratio of inner width to thickness in the web $\left(B_{w} / t_{w}\right)$ closely correlate with the stress in the flange and web-buckling, respectively.

(2) The larger the value of $\left(t_{f} / t_{w}\right)$ is, the larger the residual stress and the web-buckling index are. This is because in that situation the larger compressive plastic deformation occurs in the flange while the transformation proceeds there.

(3) The larger the value of $\left(T_{f 0}-T_{w 0}\right)$ is, the larger the residual stress and the index are. This is because in that situation the difference of thermal 
contraction between flange and web from a point immediately after rolling to a point after cooling (room temperature) becomes larger.

(4) The larger the value of $\left(S_{f} / S_{w}\right)$ is, the smaller the residual stress in the flange is. This is because the integral value of the stress over the whole area in cross-section has to be zero from the balance of force. Namely the stress in the flange with a bigger cross-sectional area becomes smaller than the stress in the web. On the contrary the value of $\left(S_{f} / S_{w}\right)$ has little influence on the stress at the center of the web height $\left(\sigma_{w 1 / 2}\right)$. The value, however, changes the stress distribution in the web.

(5) The larger the value of $\Delta T_{w}$ is, the smaller the residual stress and the index are. This is because in that situation there is more non-transformed phase ( $\gamma$ phase) in the web immediately after rolling and the larger compressive plastic deformation occurs in the web while the transformation proceeds there.

(6) The larger the value of $\Delta \mathcal{T}_{f}$ is, the smaller the residual stress and the index are. This is because in that situation there is less non-transformed phase in the flange immediately after rolling and the smaller compressive plastic deformation occurs in the flange while the transformation proceeds there.

(7) The larger the value of $\left(B_{w} / t_{w}\right)$ is, the smaller the critical buckling stress $\sigma_{\text {cr }}$ becomes. Therefore in that situation the web-buckling occurs more frequently.

\section{Conclusion}

A numerical method for the prediction of temperature and thermal stress during cooling in hot rolled H-beams has been developed by taking phase transformation into account. The temperature during cooling and the residual stress calculated by the present method agree well with the measured ones. The influence of finishing temperature and cross-sectional size on the residual stress and the webbuckling was investigated by using this method. The results obtained are as follows;

(1) The larger the thickness ratio of flange to web $\left(t_{f} / t_{w}\right)$ is and the larger the difference in finishing temperature between flange and web $\left(T_{f 0}-T_{w 0}\right)$ is, the larger the stress is and the more frequently the web-buckling occurs.

(2) The larger the ratio of cross-sectional area of flange to web $\left(S_{f} / S_{w}\right)$ is, the smaller the tensile stress in the flange is and the larger the compressive stress in the web is.

(3) Immediately after rolling, the smaller the difference between the finishing temperature in web and the finish temperature of $\gamma \rightarrow \alpha$ transformation ( $\left.T_{w}=T_{w 0}-T_{A 1}\right)$ or the less the non-transformed phase ( $\gamma$ phase) in the web is, the larger the stress is and the more frequently the web-buckling occurs.

(4) Immediately after rolling, the larger the difference between the start temperature of the transformation and the finishing temperature in flange $\left(\Delta T_{f}=T_{A 3}-T_{f 0}\right)$ or the more the non-transformed phase in the flange is, the larger the stress is and more frequently the web-buckling occurs.

(5) The larger the ratio of inner width to thickness in web $\left(B_{w} / t_{w}\right)$ is, the more frequently the webbuckling occurs.

(6) The stresses at the centers of the web height and the flange width, and the index of web-buckling can be expressed with functions of the following factors $\left(t_{f} / t_{w}, T_{f 0}-T_{w 0}, S_{f} / S_{w}, \Delta T_{w}, \Delta T_{f}, B_{w} / t_{w}\right)$. These functions can be used effectively as simplified equations for the prediction of the stresses and the web-buckling.

\section{REFERENCES}

1) I. Nakauchi, H. Ichinose, T. Yoshino and K. Marioka: Tetsu-to-Hagané, 67 (1981), S1043.

2) T. Kusakabe and Y. Mihara: Tetsu-to-Hagané, 65 (1979), 1383.

3) H. Yoshida, T. Sasaki and N. Kondo: Tetsu-to-Hagané, 63 (1977), S736.

4) G. A. Alpsten: Thermal Residual Stress in Hot-rolled Steel Members, Fritz Engineering Laboratory, Rep. No. 337.3, (1968), 66.

5) T. Kusakabe and Y. Mihara: Tetsu-to-Hagané, 65 (1979), 1375.

6) H. Yoshida, T. Sasaki, T. Tanaka and Y. Hirose: Tetsuto-Hagané, 68 (1982), 965.

7) H. Yoshida: Trans. ISIJ, 24 (1984), 212.

8) G. Birkhoff and R. S. Varga: Trans. Amer. Math. Soc., 92 (1959), 13.

9) Y. Ito, Y. Sakamoto, M. Saiki, Y. Saito, S. Takizawa and S. Higashino: Tetsu-to-Hagané, 64 (1978), S806.

10) Y. Ito, Y. Sakamoto, M. Saiki, T. Funakoshi, T. Ogino, Y. Saito, S. Higashino and N. Aoyagi: Tetsu-to-Hagané, 65 (1979), A185.

11) E. Scheil: Arch. Eisenhüttenw., 8 (1935), 565.

12) T. Nishizawa: Bull. Japan Inst. Metals, 12 (1973), 35.

13) T. Nishizawa: Bull. Japan Inst. Metals, 17 (1978), 790.

14) H. Stuart and N. Ridley: JISI, 204 (1966), 711.

15) Society of Steel Construction of Japan: JSSC, 4 (1968), No. $33,48$.

16) T. Sakai and M. Ouhashi: Tetsu-to-Hagané, 67 (1981), 2000.

17) S. Sakui, T. Sakai and Y. Sawada: J. Japan Inst. Metals, 40 (1976), 1284

18) H. Suzuki and J. Ohno: Tetsu-to-Hagané, 64 (1978), 1236. 